\title{
A CONTRIBUIÇÃO DO FOOD MILES NA LOGÍSTICA DE TRANSPORTE DO MAMÃO: DO CAMPO AO ENTREPOSTO
}

\author{
Joseane Thereza Bigaran \\ Aliotte \\ esalqlogbigaran@gmail.com \\ Universidade Estadual de \\ Campinas - UNICAMP, Campinas, \\ São Paulo, Brasil.
}

\section{Dag Mendonça Lima}

limadm@unicamp.br Universidade Estadual de Campinas - UNICAMP, Campinas, São Paulo, Brasil.

\section{Andréa Leda Ramos de} Oliveira

aleda@unicamp.br

Universidade Estadual de

Campinas - UNICAMP, Campinas,

São Paulo, Brasil.

\section{RESUMO}

Destaques: O mamão é uma das frutas mais consumidas pela população brasileira. Por ser uma fruta de alta perecibilidade sua logística depende de uma gestão eficiente. Nesse sentido, o conceito food miles busca garantir a qualidade do alimento e a redução das perdas e desperdícios, através da adoção de uma cadeia logística de distribuição e de comercialização mais eficiente, percorrendo menores distâncias entre a produção e o consumo. Objetivo: Avaliar se a distância percorrida ao longo do transporte do mamão para comercialização interfere nas perdas e desperdícios.

Desenhos/Metodologia/Abordagem: Aplicação do conceito food miles de forma quantitativa através do método Weighted Average Source Distance (WASD) para promover estratégias logísticas mais eficientes para produtos perecíveis.

Resultados: A maior parte das rotas do mamão se enquadram na categoria rotas longa e média-longa. $O$ principal resultado encontrado foi uma distância média de food miles de $1.359 \mathrm{~km}$ a partir de diversos municípios produtores e diferentes níveis de volume de produção. Este valor é classificado como uma rota de distância média-longa.

Limitações da investigação: Avaliação detalhada das práticas operacionais durante o transporte.

Implicações práticas: As longas distâncias percorridas entre a origem e destino somados aos impactos causados durante o transporte podem contribuir para um aumento dos índices de perdas e desperdícios. Isto porque durante o transporte o mamão é acondicionado em embalagens inadequadas e em caminhões não refrigerados não garantindo a preservação da fruta. Além disto, as longas distâncias implicam não só em aumento do custo de transporte, mas também numa maior emissão de CO2.

Originalidade/valor: $\mathrm{O}$ uso do conceito de food miles de forma aplicada e quantitativa permite aos tomadores de decisão pensar em uma logística mais ajustada, de modo a buscar rotas mais sustentáveis e eficientes, não só em termos de custo mas também em rotas que impactem menos o meio ambiente.

Palavras-chave: Perdas; Desperdício; CEASA. 


\section{INTRODUÇÃO}

Nos últimos anos, a preocupação com os hábitos alimentares vem ganhando cada vez mais adeptos em busca de alimentação saudável através do consumo de frutas, legumes e verduras (FLV) in natura. Mais recentemente, essa população também tem demandado alimentos produzidos próximos ao local de consumo. Para esse modelo de "produção-consumo" sustentável, a comunidade internacional científica tem denominado de food miles. O conceito foi criado pelo professor Tim Lang, em meados da década de 1990, no Reino Unido, durante o evento Sustainable Agriculture Food and Environment (SAFE) e descrito pela primeira vez em um relatório intitulado "The Food Miles Report: The dangers of long-distance food transport" (Kemp et al., 2010). O termo food miles, que traduzido para o português significa "milhas de alimentos", tem sido pesquisado continuamente, não só por tratar da produção próxima ao local de consumo, mas também por se preocupar com a qualidade dos alimentos que serão consumidos, além de considerar implicações importantes para a sustentabilidade econômica, ambiental e sociocultural. Milhas de alimentos é a distância entre o local da produção do alimento até o local onde são finalmente comprados ou consumidos (Watkiss et al., 2005; Sirieix et al., 2008; Caputo et al., 2013; Van Passel, 2013). A agricultura sustentável é uma questão política importante, e é por isso que pesquisadores e tomadores de decisão estão tratando o problema para fora da fazenda, com atenção especial para a questão das milhas de alimentos (Sirieix et al., 2008).

Porém, antes da amplitude do conceito food miles, a preocupação com a comida local já era premissa de muitas outras pesquisas (Feenstra, 1997; Feagan, 2007; Sims, 2009; Caspi et al., 2012).

A grande questão é que food miles tem um repertório que vai muito além da comida local, por considerar questões de sustentabilidade ambiental, econômica e social. Sirieix et al. (2008) explica que food miles tem implicações em termos de uso de energia e poluentes. Pirog e Benjamin (2003) considera que as milhas de alimentos são tão importantes que as considera como um indicador de desenvolvimento sustentável. É por isso que são extensas as pesquisas que discutem a importância do conceito food miles em se tratando de emissões de CO2 (Weber; Matthews, 2008; Coley et al., 2009; Coley et al., 2011; Kissinger, 2012; Pratt, 2013; Mosammam et al., 2018; Tobarra et al., 2018, Malak-Rawlikowska et al., 2019).

Outra questão também muito discutida em pesquisas que abordam o conceito food miles é a percepção dos consumidores quanto as milhas de alimentos. Schnell (2013) explica que os consumidores ainda estão muito confusos sobre o que é o consumo de alimentos produzidos localmente, pois eles não entendem o tema como uma questão espacial (distância), apenas entende o conceito como uma forma de valorização do alimento produzido próximo. Nessa linha, Bazzani e Canavari (2017) descreve que o significado de "local" deve ser explicado mais em termos de ligação a uma área geográfica do que em termos de milhas de alimentos. $O$ conceito de local vai além do que simplesmente distância. Para as pessoas, o alimento é uma expressão da identidade de uma região ou de um país. Para Caputo et al. (2013), se no rótulo da embalagem houver informações sobre o tempo e o número de milhas percorridas pelo alimento, maiores serão os efeitos positivos sobre o bem-estar do consumidor do que apenas saber a quantidade de emissão de $\mathrm{CO} 2$.

Com a crescente preocupação dos consumidores com o meio ambiente e as mudanças climáticas, espera-se que o mercado de produtos sustentáveis se expanda significativamente no futuro (Akaichi et al., 2017). Isso demanda uma melhor eficácia dos sistemas de transportes através da aplicabilidade de food miles sempre que possível. A forma como o sistema alimentar está organizado contribui substancialmente ao aquecimento global e às mudanças climáticas (Sirieix et al., 2008). Além disso, as energias usadas pelas cadeias alimentares são muitas vezes punidas por uma logística ineficiente (Schlich et al., 2006; Coley et al., 2009). Dessa forma, um aumento em milhas de alimentos leva a aumentos nos encargos ambientais, sociais e econômicos associados ao transporte (Watkiss et al., 2005).

No Brasil, o conceito ainda é pouco conhecido, mas tem ganhado adeptos por se tratar de um tema bastante promissor, de importante impacto e contribuição à Segurança Alimentar e Nutricional (SAN). Diante de uma população cujo percentual de obesidade vem crescendo significativamente e como consequência o aumento de Doenças Crônicas Não Transmissíveis (DCNT) (diabetes mellitus, hipertensão arterial e outras), o aumento da oferta de FLV é um caminho para o governo fomentar políticas públicas de SAN com acesso à alimentação saudável. Segundo Gonzáles-Muniesa et al. (2017), mais de 2 bilhões da população mundial está obesa ou em condições de sobrepeso. A obesidade e o sobrepeso, além de impactar na qualidade de vida das pessoas, estão associados a diferentes componentes multifatoriais: dieta, atividade física, histórico familiar, preferências culturais, práticas alimentares e comportamentos associados ao consumo de alimentos (González-Muniesa et al., 2017).

Na esfera ambiental, a preocupação é com as mudanças climáticas e o impacto dessas mudanças sobre as condições e a qualidade de vida das populações, pois afetam diretamente na decisão dos consumidores em adquirir produtos que sejam sustentáveis e responsáveis ambientalmente (Weber; Matthews, 2008). Conforme Watkiss et al. (2005), quanto maiores às distâncias percorridas pelos alimentos, maiores serão os encargos ambientais, sociais e econômicos 
associados ao transporte. Estes incluem emissões de dióxido de carbono, poluição do ar, congestionamento, acidentes, ruído e consumo de combustível. Em países industrializados, como a Grã-Bretanha e os EUA, os alimentos estão percorrendo maiores distâncias até chegar ao consumidor. Entre 1978 a 1999, as distâncias com o transporte de alimentos na Grã-Bretanha aumentaram 50\% (Pirog; Benjamin, 2003). No Reino unido, desde 1978, o volume anual de alimentos transportados por veículo pesado, aumentou $23 \%$ e a distância média de cada viagem subiu mais de $50 \%$ (Watkiss et al., 2005).

Maiores distâncias também estão associadas às maiores perdas. Quanto mais tempo as FLV permanecerem em percurso, maior a possibilidade de perda do produto, que começa a sofrer deterioração desde o momento em que é colhido. Deste modo, a abordagem de uma produção local viabiliza a teoria do conceito food miles, através da prática de rotas curtas de transporte. Por isso, propostas de redução dos níveis de perdas e desperdícios ao longo da cadeia de FLV devem ser consideradas como um importante fator de contribuição à oferta e disponibilidade de alimentos, e também, de contribuição ao menor impacto ambiental, seja pela diminuição nas emissões de gases do efeito estufa, seja pela utilização consciente dos recursos naturais.

Segundo cálculos da FAO, as perdas de alimentos no mundo giram em torno de $30 \%$, o que representa aproximadamente 1,3 bilhões de toneladas por ano (Gustavsson et al., 2011). Segundo os autores, estima-se que aproximadamente um terço das frutas e hortaliças frescas são jogadas fora porque sua qualidade caiu abaixo do limite de aceitação. A perda de alimentos também contribui para importantes impactos ambientais, tais como: o não uso racional dos recursos hídricos, energéticos, o uso e a utilização da terra em que foram produzidos os alimentos que não chegaram ao seu destino final, bem como as emissões desnecessárias de gases de efeito estufa na atmosfera (FAO, 2013). A redução das injúrias nos alimentos contribuiria, no limite, para a redução do desperdício, mas o seu efeito imediato é o de redução nas perdas comerciais. Um aumento de oferta de alimentos combinada a redução de custos provocada pela diminuição das perdas comerciais, levariam possivelmente a uma redução de preço ao consumidor final.

A eliminação ou a minimização destas perdas apresentam as seguintes vantagens: (1) o suprimento de alimento pode ser significativamente aumentado, sem aumentar a área de cultivo e sem utilizar grandes quantidades de energia, água e capital; (2) eliminação de energia gasta para produzir e comercializar o alimento perdido; (3) redução na poluição em decorrência da redução da matéria orgânica em decomposição; (4) melhor satisfação das necessidades do consumidor e melhor nutrição, com a mesma quantidade de energia, terra, água e trabalho (Hirschbruch, 1998).
Aspectos relacionados ao ambiente físico, instalações e a relação com condições de higiene, incluindo manipuladores, devem ser planejados para que se possa minimizar perdas e desperdícios. Ações pontuais tais como a padronização de processos e serviços, com a criação de rotinas e procedimentos técnicos operacionais, treinamento da equipe e controle das atividades por meio de análises devem ser implementadas para a redução das perdas (Hirschbruch, 1998).

Assim, durante toda a cadeia de suprimentos o alimento pode sofrer perdas que estão associadas à sua produção, colheita e pós-colheita, beneficiamento, distribuição e comercialização (Parfitt et al., 2010). Portanto, a produção de alimentos em que a região de oferta esteja próxima à região de demanda, pode contribuir para níveis de perdas e desperdícios reduzidos, pois, melhora a utilização adequada dos recursos naturais, aumentando a oferta e a disponibilidade desses alimentos, além de favorecer o acesso a eles em qualidade e a preços adequados. Segundo Weber; Matthews (2008), a procura cada vez maior por alimentos orgânicos e cultivados localmente, tanto nos EUA quanto na Europa, mostram que os consumidores estão preocupados com a forma de produção empregada e local de origem. Portanto, as "milhas de alimentos" tornam-se objeto de debate sobre a sustentabilidade alimentar (Van Passel, 2013). Neste sentido, ao se avaliar a cadeia de suprimentos identificando em que etapas ou em que condições estão associados os maiores níveis de perdas e desperdícios, se poderia propor estratégias e ações, a fim de tornar essa cadeia mais eficiente e com alimentos sendo produzidos mais próximos às regiões demandantes.

Todas essas considerações demandam pesquisas e estudos que tenham por finalidade tentar medir e reduzir as milhas de alimentos, evitando perdas e desperdícios. Em se tratando de FLV, no Brasil, o mercado se mostra bastante pulverizado, de modo que esses produtos são comercializados por grandes atacadistas, como é o caso das Centrais de Abastecimento (CEASA). Cunha e Campos (2008) descrevem que as CEASA movimentam aproximadamente 14 milhões de toneladas de produtos hortigranjeiros, o que representa U\$ 10 bilhões anuais. E quando considerados os demais produtos e serviços que comercializa, esse valor é superior ao das vendas das duas principais redes varejistas brasileiras somadas.

Ainda segundo Cunha e Campos (2008), as CEASA formam uma rede descentralizada, com cerca de 40 unidades administrativas, 53 unidades comerciais principais e outras unidades de menor porte, tornando-se a principal responsável pelo abastecimento alimentar da população urbana brasileira. Outro fator diferencial é que as CEASA são agentes operacionais importantes nos sistemas de agricultura de governos locais, centralizando, ainda que de forma assistemática, iniciativas pertinentes às políticas agrícolas estaduais, 
bem como políticas de segurança alimentar. Uma vantagem não explorada neste sentido reside no fato de que as principais centrais coletam sistematicamente dados estatísticos sobre quantidade comercializada e origem dos produtos, o que permite identificar os municípios e microrregiões ofertantes, categorizando sua relevância em quantidade de oferta, a diversificação ou especialização de sua pauta comercial e a sazonalidade dessa oferta (Cunha, 2015).

Quanto à comercialização de FLV, tradicionalmente composta por produtores, atacadistas e varejistas, estes vêm passando por alterações, ora pela conexão direta dos grandes varejistas com os produtores, ora pela revalorização do atacadista. A maioria dos atacadistas de hortifrútis opera nas CEASA. Estes entrepostos têm capacidade de concentrar boa parte do mercado, eliminar concorrentes e prestar serviços especializados (Oliveira; Rocha, 2005).

Considerando a tendência dos consumidores por alimentos mais frescos e com qualidade, talvez seja importante saber situar de onde vem e para onde vão as FLV comercializadas pelas CEASA, quais as distâncias percorridas e compreender suas práticas logísticas e de comercialização. Van Passel (2013) explica que uma das variáveis ao se estudar "milhas de alimentos" é compreender as externalidades do transporte levando em consideração seus diferentes modos e sua eficiência.

Isto posto, este artigo tem por objetivo avaliar se a distância percorrida durante o transporte do mamão para comercialização interfere nas perdas e desperdícios. Para tanto, foram identificadas as rotas praticadas pelo mamão comercializado na CEASA Campinas e aplicado o método Weighted Average Source Distance (WASD) para cálculo da rota food miles e, assim, identificar as práticas de gestão de transporte e comercialização capazes de mitigar os índices de perdas e desperdícios.

\section{MÉTODO}

\section{Local da pesquisa}

Para o desenvolvimento da pesquisa foi selecionada a CEASA Campinas. Os trabalhos começaram em 1972, mas somente em 1989 o entreposto foi municipalizado, sendo o controle acionário pertencente à Prefeitura de Campinas. $\mathrm{Na}$ época, a finalidade era aproximar a produção agrícola de produtos nacionais e importados aos consumidores, estimulando a comercialização e o consumo de hortifrutigranjeiros. $O$ entreposto situa-se às margens da Rodovia D. Pedro I, com fácil acesso a Rodovia dos Bandeirantes e Anhanguera. Possui uma área física de $300 \mathrm{mil}^{2}$ e tem passado por constantes melhorias. São mais de 580 atacadistas (chama- dos de permissionários) em cerca de 940 lojas (chamadas de boxes e pedras). Por mês, o mercado comercializa cerca de 50 mil toneladas de frutas, verduras e legumes, em torno de $\mathrm{R} \$ 140$ milhões mensais (CEASA Campinas, 2020).

\section{Produto selecionado}

O mamão foi selecionado por ser uma das frutas mais comercializadas na CEASA Campinas em termos de volume em toneladas, também pela sua perecibilidade e variedade de locais de produção.

\section{Coleta de dados}

Os dados levantados para o estudo, como rotas de transporte de mamão (campo - entreposto), volume e valores financeiros, foram obtidos através do site do Programa Brasileiro de Modernização do Mercado Hortigranjeiro (Prohort). Os dados são referentes ao ano de 2018. As distâncias foram levantadas utilizando o Google Maps. Também foram realizadas visitas ao entreposto para conhecer as práticas de transporte e comercialização adotadas pelos atacadistas por meio de entrevistas, bem como conversas com os gestores do mercado de FLV. As entrevistas foram realizadas no box ou no módulo de comercialização (pedra). Foram entrevistados seis atacadistas responsáveis pelo volume de compra agregado de 2,3 mil ton/mês. Eles representam $54,97 \%$ do total de mamão comercializado na CEASA Campinas. Buscou-se conhecer características de compra e venda, e, a percepção dos atacadistas sobre a logística da cadeia do mamão.

\section{Análise dos dados}

Para o cálculo ponderado das distâncias utilizou-se o método WASD empregada por Pirog e Benjamin (2003) em trabalho similar, cuja distância média ponderada é calculada a partir das origens do produto para presumir uma distância única, que combina informações de distâncias entre local da produção ao ponto de venda e o volume de alimento transportado. A equação WASD é dada por:

$$
W A S D=\frac{\sum(m(k) x d(k))}{\sum m(k)}
$$

em que:

$k=$ Diferentes pontos de localização da produção

$m=$ Volume de cada ponto da produção

d = Distância de cada ponto de produção para cada ponto de venda 
Quando se trata da pesquisa de um único produto, com diversas rotas de origem, mas com um único destino, o cálculo da distância média ponderada é o mais eficiente e é por isso que é relativamente fácil calcular food miles para um único produto não processado (Pirog; Benjamin, 2005). Pirog et al. (2001) também usaram o método WASD para calcular o aumento do food miles para uvas de mesa consumidas no estado de lowa nos EUA, para um período de três diferentes anos.

O método WASD é um indicador criado por Carlsson-Kanyama (1997) para calcular uma distância única em que são combinadas informações sobre distâncias entre produtores, consumidores e volume. Para ela, o resultado obtido através do método também ajuda em cálculos para estimativas de possíveis riscos ambientais, como emissões de poluentes.

Nas últimas décadas, diferentes métodos foram criados para calcular milhas de alimentos e sendo substituídos por técnicas mais avançadas (Mosammam et al., 2018). A equação WASD já foi usada por diversos pesquisadores que estudam o sistema alimentar americano para calcular food miles (Pirog; Benjamin, 2003).

Rajkumar e Jacob (2010) empregaram o método WASD para calcular o aumento de food miles nos mercados de hortaliças para um varejo organizado em Chennai na Índia. Nicholson et al. (2011) aplicaram o método WASD para comparar diferentes cenários de possíveis localizações de origens para a cadeia de suprimentos de uma indústria de laticínios, em que o objetivo era reduzir os custos dessa cadeia através de um modelo de transbordo. Atallah et al. (2014) também utilizaram o WASD para calcular uma distância de origem não local para determinados padrões de consumo. Schmitt et al. (2017) usaram o WASD para comparar graus de localidade entre duas diferentes fontes de origem de queijo. Mosammam et al. (2018) aplicaram o WASD para calcular food miles para um grupo de 14 produtos agrícolas importados pelo Irã.

Para melhor posicionar o food miles do mamão e apoiar a tomada de decisão dos agentes desta cadeia, o índice foi classificado em quatro categorias em função da distância das rotas entre a origem e o destino, como ilustrado na Tabela 1.

Tabela 1. Classificação das categorias da rota food miles do mamão

\begin{tabular}{|c|c|}
\hline Classificação da rota food miles & Distância \\
\hline Curta & $<400$ \\
\hline Média-curta & $401-1.000$ \\
\hline Média-longa & $1.001-1.600$ \\
\hline Longa & $>1.601$ \\
\hline
\end{tabular}

Fonte: Elaborado pelos autores.

\section{RESULTADOS E DISCUSSÃO}

\section{Perfil da CEASA Campinas}

As CEASAs brasileiras, no exercício 2018, ofertaram 13 milhões de toneladas de produtos hortifrutigranjeiros. Os estados que mais contribuíram para a oferta de produtos foram: São Paulo (27,5\%), Minas Gerais (19,5\%), Rio de Janeiro $(18,2 \%)$, Paraná (8,8\%), Goiás (7\%) (Prohort, 2018).

$O$ ranking de comercialização de hortigranjeiros dos entrepostos atacadistas, em termos de volume é: (1ㅇ) CEAGESP São Paulo, (2을 CEASA Rio de Janeiro, (3ํ) CEASA Grande BH, (4ㅇ) Mercado do Produtor de Juazeiro, (5으) CEASA Goiânia, (6) CEASA Curitiba, (7을 CEASA Recife, (8ㅇ) CEASA Porto Alegre, (9ㅇ) CEASA Campinas e (10ㅇ) CEASA Salvador (CONAB, 2019).

A CEASA Campinas, no mesmo período de 2018, ofertou no mercado de hortifrutigranjeiros um volume físico de aproximadamente $604 \mathrm{mil}$ toneladas, das quais $327 \mathrm{mil}$ toneladas são frutas e 274 mil são hortaliças. Esses resultados, quando comparados ao ano de 2017, mostraram-se 4,5\% menor. Parte dessa redução deve-se à greve dos caminhoneiros ocorrida em maio de 2018. As dez FLV mais comercializadas em volume foram por ordem: batata, melancia, laranja, banana, cebola, mamão, tomate, maçã, abacaxi e manga (CEASA Campinas, 2019). Esse montante demonstra o potencial desse mercado, mostrando sua importância quanto ao fornecimento de frutas e hortaliças, em Campinas e região.

Em relação ao volume financeiro, a movimentação também é significativa para a região, pois o setor movimentou em 2018, aproximadamente, 1,5 bilhões de reais (CEASA Campinas, 2019).

\section{Relevância da comercialização de mamão na CEASA Campinas}

Em 2018, o Brasil produziu 1.060,4 mil toneladas de mamão, distribuídas em 27,2 mil hectares, sendo a maior parte da produção nas regiões sudeste e nordeste (FAO, 2018). Cerca de $0,3 \%$ da produção brasileira é comercializada pela CEASA Campinas.

O mamão apresenta grande importância socioeconômica para a fruticultura nacional (Lucena, 2016). De acordo com a Empresa Brasileira de Pesquisa Agropecuária (Embrapa), do Ministério da Agricultura, Pecuária e Abastecimento, o Brasil é o segundo maior produtor de mamão do mundo, atrás da Índia, e um dos principais exportadores mundiais, com destino especialmente para o mercado eu- 
ropeu. As principais cultivares brasileiras são: Sunrise Solo - mais conhecidas como mamão Havaí, Papaya ou Amazônia; Improved Sunrise Solo - mamão Havaí; Tainung no 1 e Tainung no 2 - popularmente conhecidos como formosa (Embrapa, 2020). O Brasil também configura como segundo maior exportador do mundo, no entanto, praticamente $98 \%$ da produção de mamão é absorvido pelo mercado interno (Lucena, 2016).

No Brasil, o mamão originou-se na Bacia Amazônica, com favorecimento de clima tropical, mas atualmente, a produção concentra-se nas regiões do Sul da Bahia; Norte do Espírito Santo; Oeste Baiano; Chapada do Apodi, no Rio Grande do Norte; Norte de Minas Gerais; e Baixo Jaguaribe/Vale do Acaraú, no Ceará (Lucena, 2016).

Na década de 70, o estado de São Paulo era o maior produtor de mamão do Brasil, representando quase $50 \%$ de toda produção, mas devido ao surgimento do vírus do mosaico do mamoeiro a cultura migrou para outras regiões do país, como o nordeste do Pará, extremo sul da Bahia e norte do Espírito Santo. Já na década de 80, a migração decorreu por motivos comerciais e bem menos fitossanitários (Ruggiero et al., 2011, apud Lucena, 2016).

Atualmente os principais polos produtores de mamão do Brasil são os que fornecem a fruta para a CEASA Campinas (Figura 1).

Os principais estados produtores são Espírito Santo e na sequência Bahia, que juntos detêm $65 \%$ da produção nacional, cerca de 691 mil toneladas (Figura 1) (IBGE, 2018). O principal município produtor de mamão no Brasil é Pinheiros, no estado de Espírito Santo, percorrendo 1.200 $\mathrm{km}$ até Campinas, considera como uma distância média-longa. Já em Parauapebas, no Pará, o mamão precisa vencer uma distância de $2.200 \mathrm{~km}$ até a CEASA Campinas, considerada longa distância.

Já no estado da Bahia, o destaque é o município de Prado. $O$ mamão desta região precisa percorrer cerca de 1.600 $\mathrm{km}$ para ser comercializado na CEASA Campinas. Da mesma

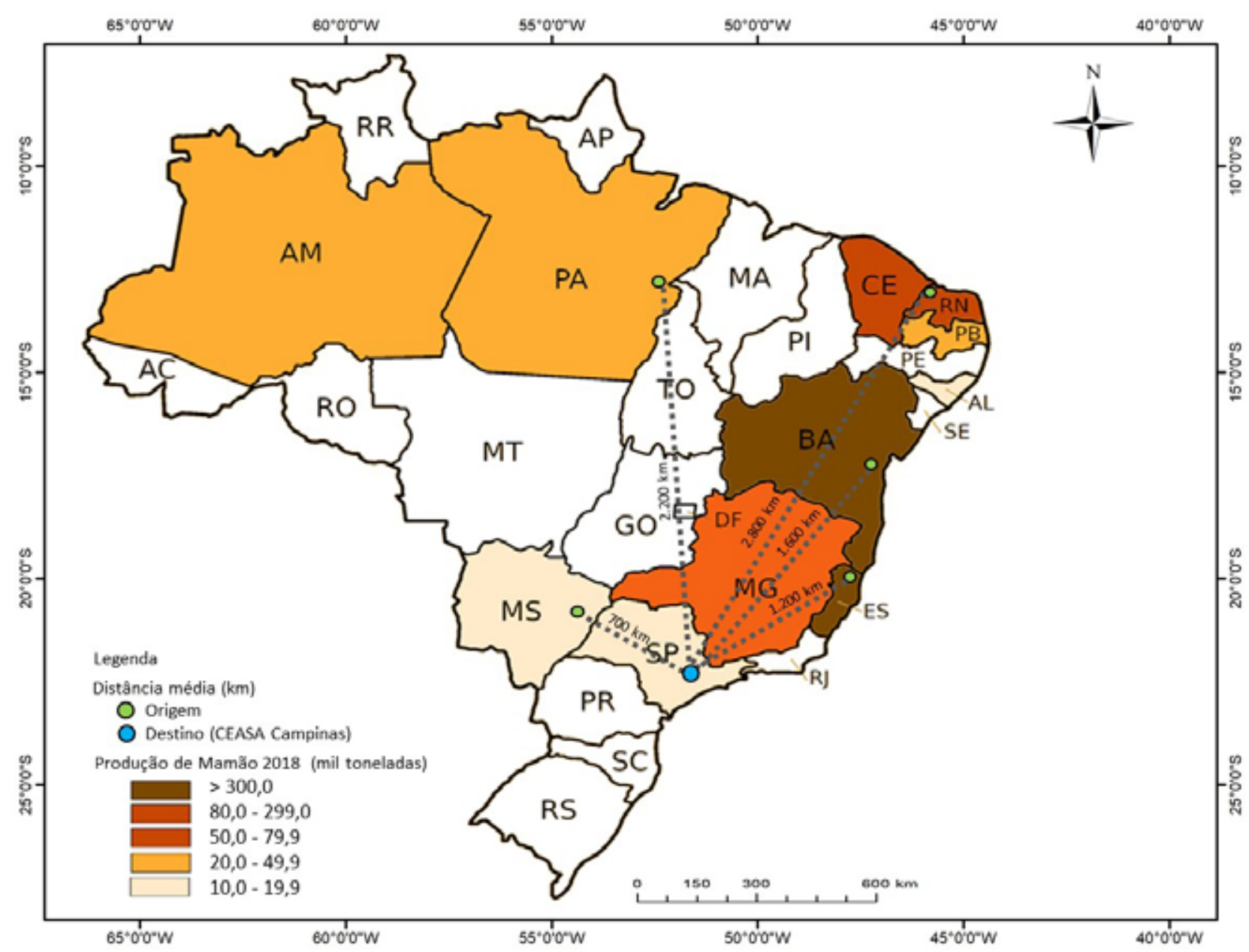

Figura 1. Principais estados produtores de mamão com destino a Ceasa Campinas Fonte: Elaborado pelos autores a partir de IBGE (2018). 
forma acontece com a produção de Apodi, no Rio Grande do Norte, este município que também faz divisa com o Ceará percorre uma distância de aproximadamente $2.800 \mathrm{~km}$ até CEASA Campinas (Figura 1).

Em 2018, foram comercializadas 36 mil toneladas de mamão, $6 \%$ do volume hortifrutigranjeiro comercializado pela CEASA Campinas. Esse volume garantiu ao mamão o status do 6 o produto hortifrutigranjeiro mais comercializado no entreposto (Prohort, 2018).

Quando comparado volume dentro do ranking frutas, o mamão ganhou a 4a posição, sendo $11 \%$ do volume total de frutas, atrás apenas da melancia, laranja e banana. São 9 os estados que forneceram mamão para o entreposto (Tabela 2) (BRASIL, 2018).

Tabela 2. Estados fornecedores de mamão para a CEASA Campinas por volume

\begin{tabular}{|c|c|}
\hline Estado & Volume (toneladas) \\
\hline Bahia & 19.813 \\
\hline Espírito Santo & 11.565 \\
\hline Minas Gerais & 3.386 \\
\hline Rio Grande do Norte & 1.022 \\
\hline São Paulo & 401 \\
\hline Santa Catarina & 29 \\
\hline Sergipe & 20 \\
\hline Rio Grande do sul & 11 \\
\hline Paraíba & 5 \\
\hline Subtotal mamão & 36.252 \\
\hline Total de Frutas Comercializadas na & 327.648 \\
\hline CEASA Campinas & Fon \\
\hline
\end{tabular}

Fonte: Elaborado pelos autores a partir de BRASIL (2018).

Os estados da Bahia e Espírito Santo, juntos, representam $87 \%$ do volume total do mamão comercializado na CEASA Campinas em 2018 (Tabela 2). A Bahia é o estado que mais ofertou mamão para o entreposto, $55 \%$ do volume total, valor superior à soma dos outros oito estados que comercializa o fruto, total de $45 \%$.

Ao considerar o total de volume financeiro, os estados da Bahia e Espírito Santo, representam 88\% dos recursos financeiros totais para o mesmo período. Chama atenção o estado de Sergipe, apesar de representar somente $0,05 \%$ do volume em toneladas comercializado, seu preço $\mathrm{R} \$ \mathrm{Kg}$ é de $\mathrm{R} \$ 5,98$, os mais elevados dos nove estados analisados.
Em geral, 68 municípios brasileiros forneceram mamão para o entreposto em 2018, dos quais, 21 encontram-se na Bahia e 14 em Minas Gerais (Tabela 3).

Tabela 3. Número total de municípios produtores de mamão para a CEASA Campinas

\begin{tabular}{|c|c|}
\hline Estado & Municípios (total) \\
\hline Bahia & 21 \\
\hline Minas Gerais & 14 \\
\hline Espírito Santo & 12 \\
\hline São Paulo & 11 \\
\hline Rio Grande do Norte & 3 \\
\hline Santa Catarina & 3 \\
\hline Rio Grande do sul & 2 \\
\hline Paraíba & 1 \\
\hline Sergipe & 1 \\
\hline Total & 68 \\
\hline
\end{tabular}

Fonte: Elaborado pelos autores a partir de BRASIL (2018).

As cidades baianas de Itabela, Eunápolis, Porto Seguro, São Felix do Coribe e São Jesus da Lapa formam o top 5 da Bahia em volume de mamão comercializado na CEASA Campinas. Esses cinco municípios são tão expressivos, que juntos, representam $78 \%$ do volume total fornecido pela Bahia e $43 \%$ do volume total de todos os estados.

Quando analisado o top 5 para o Espírito Santo, as cidades de Linhares, Pinheiros, Boa Esperança, Montanha e São Mateus são responsáveis por $91 \%$ do volume de mamão do estado comercializado no entreposto de Campinas e representa $29 \%$ do total de volume dos estados.

\section{Principais rotas de comercialização de mamão junto à CEASA Campinas}

Embora o mamão seja uma fruta perecível e necessite de um modelo de transporte eficiente, os principais municípios produtores estão localizados a uma distância superior a $1.500 \mathrm{~km}$ e classificadas nas categorias mais superiores do food miles, média-longa e longa (Tabela 1). Vale observar que as dez cidades produtoras mais distantes do entreposto representam $15 \%$ do volume total de mamão (Tabela 4).

O município de Lajes, no estado do Rio Grande do Norte, por exemplo, está a $2.881 \mathrm{~km}$ de distância de Campinas/SP sendo uma rota longa. Em contraponto, o local de produção mais próxima à CEASA encontra-se no próprio município de Campinas, a $11 \mathrm{~km}$ de distância sendo uma rota curta. 
Tabela 4. Ranking dos dez municípios de maior distância até a CEASA Campinas

\begin{tabular}{|c|c|c|}
\hline Municípios/UF & $\begin{array}{c}\text { Distância } \\
(\mathbf{k m})\end{array}$ & $\begin{array}{c}\text { Volume } \\
\text { omercializado (t) }\end{array}$ \\
\hline Lajes/RN & 2.881 & 4 \\
\hline Baraúna/RN & 2.825 & 873 \\
\hline Mossoró/RN & 2.780 & 145 \\
\hline Baraúna/PB & 2.659 & 5 \\
\hline Neópolis/SE & 2.268 & 20 \\
\hline São Félix/BA & 1.853 & 11 \\
\hline Una/BA & 1.625 & 702 \\
\hline Belmonte/BA & 1.594 & 347 \\
\hline Porto Seguro/BA & 1.585 & 3.173 \\
\hline Santa Cruz Cabrália/BA & 1.582 & 293 \\
\hline
\end{tabular}

Fonte: Elaborado pelos autores a partir de BRASIL (2018).

Tabela 5. Ranking dos dez municípios de maior volume até a CEASA Campinas

\begin{tabular}{|c|c|c|c|}
\hline Municípios/UF & $\begin{array}{c}\text { Volume } \\
\text { comerciali- } \\
\text { zado (t) }\end{array}$ & $\begin{array}{c}\text { Participa- } \\
\text { ção (\%) }\end{array}$ & $\begin{array}{c}\text { Dis- } \\
\text { tância } \\
\text { (km) }\end{array}$ \\
\hline Itabela/BA & 5.886 & 16,2 & 1.419 \\
\hline Eunápolis/BA & 3.391 & 9,4 & 1.522 \\
\hline Porto Seguro/BA & 3.173 & 8,8 & 1.585 \\
\hline Linhares/ES & 3.072 & 8,5 & 1.140 \\
\hline Pinheiros/ES & 2.841 & 7,8 & 1.165 \\
\hline Boa Esperança/ES & 2.266 & 6,3 & 1.149 \\
\hline São Félix do Coribe/BA & 1.611 & 4,4 & 1.471 \\
\hline Bom Jesus da Lapa/BA & 1.401 & 3,9 & 1.560 \\
\hline Montanha/ES & 1.337 & 3,7 & 1.224 \\
\hline Lassange/MG & 1.291 & 3,6 & 826 \\
\hline Subtotal & 26.270 & 72,5 & 1.340 \\
\hline $\begin{array}{c}\text { Total Comercializado na } \\
\text { CEASA Campinas }\end{array}$ & 36.252 & & \\
\hline $\begin{array}{c}\text { Distância Média Pondera- } \\
\text { da (Food Miles) }\end{array}$ & & & 1.359 \\
\hline
\end{tabular}

Fonte: Elaborado pelos autores a partir de BRASIL (2018).

Considerando as distâncias de todas as rotas de transporte de mamão praticadas até a CEASA Campinas ponderada pelo volume de cada origem, chegou-se ao resultado que demonstra a distância média percorrida, a partir do cálculo do método WASD. Portanto, a distância média ponderada de origem-destino para o transporte do mamão obtida é de $1.359 \mathrm{~km}$ (Tabela 5), no extrato médio-longo da escala de classificação do food miles definido na Tabela 1. Se apontarmos para a distância média ponderada dos maiores produtores, o percurso médio sinaliza para $1.340 \mathrm{~km}$ (Tabela 5). Isto se deve ao grande volume proveniente destas rotas, mas chama a atenção que as demais apontam para rotas ainda mais longas entre o produtor e o entreposto de destino (Figura 2).
O município mais distante e que ocupa a terceira posição em volume comercializado é Porto Seguro, localizado no litoral baiano, leste do Estado (Figura 2).

Ao considerar a rota mais longa, $2.881 \mathrm{~km}$, em comparação ao resultado food miles, equivale a rodar 2,1 vezes a distância WASD (Figura 2).

As dez rotas que mais fornecem mamão para a CEASA Campinas somam $72,5 \%$ do volume total. Dessas, nove rotas ultrapassam os $1.100 \mathrm{~km}$ até o entreposto, consideradas rotas que percorrem distâncias média-longas.

De acordo com Marques e Caixeta-Filho (2000), as distâncias superiores a $1.000 \mathrm{~km}$ em que o transporte da fruta é a granel, somado a maus cuidados no acondicionado, induz a danos ao produto, de modo que, a carga pode chegar ao entreposto em mau estado de conservação e de apresentação ao consumidor, ocasionando perdas. Schnell (2013) afirma que ao longo de suas pesquisas, um número bastante citado entre os pesquisadores é de que os alimentos viajam em média $2.414 \mathrm{~km}$, mas que seria viável a prática da "dieta das cem milhas", em que as pessoas deveriam consumir alimentos o máximo possível dentro de 100 milhas (equivalente a $160 \mathrm{~km}$ ) distantes de suas casas.

Desse modo, conclui-se que a média ponderada se mostrou alta, ou seja, o mamão percorre longas distâncias até chegar ao entreposto de Campinas.

Na tentativa de atender o conceito food miles, em que o consumidor dá preferência a produtos produzidos próximos ao local de consumo, infere-se que o mamão deveria ter sua maior participação de oferta nos municípios situados no estado de São Paulo, pois as distâncias são menores e consequentemente a colheita poderia ser feita mais próxima ao ponto ótimo de amadurecimento do fruto, o que neste caso, também agregaria maiores propriedades organolépticas e sensoriais.

Todavia, o Brasil possui grande extensão territorial, e, portanto, condições climáticas e de solo, além do valor de aluguel da terra são condições que precisam ser mais bem avaliadas. De qualquer modo, práticas de transporte e comercialização também são fatores importantes a serem ponderados. No caso do mamão, vale verificar se os modelos de produção atual seriam capazes de evitar o vírus do mamoeiro.

\section{Principais práticas de transporte e comercialização de mamão}

O mamão está entre as frutas que mais percorrem longas distâncias até chegar à CEASA Campinas. Por ser uma fruta de rápida perecibilidade, durante o transporte podem 


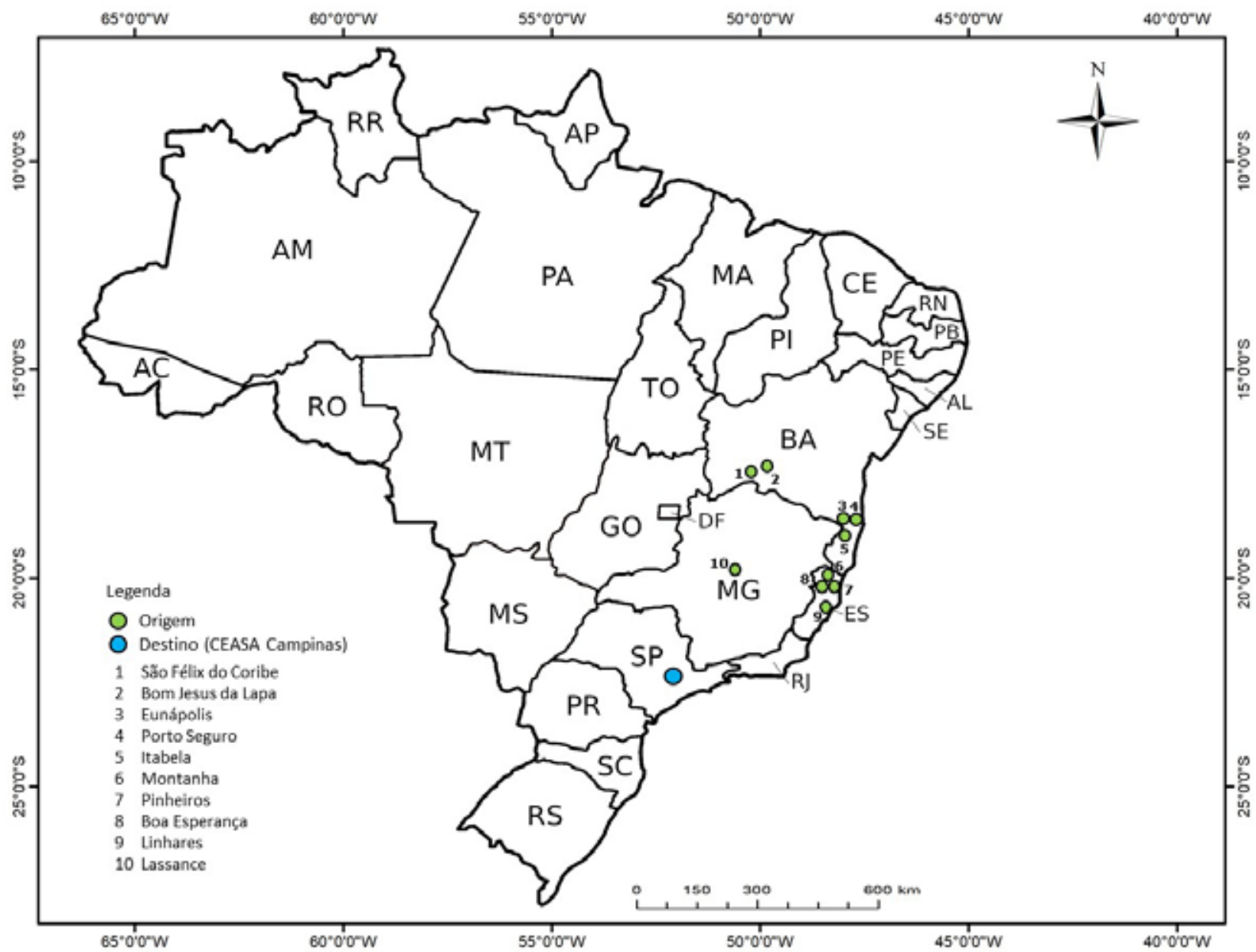

Figura 2. As dez principais rotas com maior volume com destino a Ceasa Campinas

Fonte: Elaborado pelos autores a partir de IBGE (2018).

ocorrer perdas de características sensoriais, o que consequentemente desagrega valor ao produto. Por isso, um dos grandes gargalos a serem superados é o tipo de transporte empregado.

Grande parte dos atacadistas opera com transporte a granel, em que os mamões são acondicionados em caixas de madeira, geralmente em caminhões de carroceria aberta, cobertos com lona, às vezes em caminhões baú. Esse modelo tradicional de transporte provoca danos mecânicos e de amadurecimento precoce. Os atacadistas também disseram utilizar os serviços de transporte de empresas terceirizadas ou mesmo de motoristas autônomos. Portanto, o transporte refrigerado não é prática comum deste seguimento.

Apesar dos atacadistas terem acesso ou possuírem câmaras frias para o acondicionamento do mamão, o que garante maior vida útil do produto, em sua grande maioria, eles não a utilizam. Esses atacadistas avaliam a qualidade do mamão no próprio entreposto quando chegam os caminhões para descarga, ou, em alguns casos, por meio de visitas periódicas no local da produção. Aqueles que relataram não avaliarem a qualidade do mamão disseram trabalhar com fornecedores conhecidos, o que para eles é garantia de qualidade confiável.

Quanto aos procedimentos de classificação e reclassificação, os atacadistas disseram ser uma prática rotineira durante a comercialização e que neste caso específico, essas operações, ao contrário de outras frutas, são manuais. Grande parte deles realizam operações de transbordo. Essas atividades (classificação, reclassificação e operações de transbordos) podem estar associadas à menor eficiência da cadeia logística, podendo contribuir para maiores custos, devido a maior necessidade de mão de obra e consequentemente maiores níveis de perdas da fruta.

Os dados apontam que a relação comercial é de compra e venda sem relação direta com o meio de produção, e que, a maioria dos permissionários entrevistados atuam apenas como agente de comercialização e que quase não há relação de produção. Isto pode estar associado a um menor controle nas etapas da cadeia que envolve área plantada e colhida, bem como maior controle dos padrões de sanidade e da qualidade do mamão a ser comercializado. 
Para a maioria dos atacadistas, a embalagem utilizada ainda é a caixa de madeira, mas alguns utilizam também outras embalagens como a de papelão, caixas plásticas e nichos que envolvem as frutas podendo ser de vários materiais. Ainda segundo os permissionários entrevistados, as etapas que estão mais associadas às perdas da qualidade do mamão estão no transporte (maiores distâncias, tipo de transporte, tipo de embalagem), nas operações de transbordo e no inadequado dimensionamento da compra.

Via de regra, considerando a perecibilidade do mamão, o ideal seria a fruta ser embalada em caixas de papelão e o transporte ser por caminhão refrigerado. Entretanto, o transporte refrigerado é pouco utilizado, pois encarece o transporte (Caldarelli et al., 2009). Ou seja, o custo do transporte por km rodado nesse caso é maior quando comparado ao modo de transporte tradicional. Estudos mostram que o aumento no tempo de conservação do mamão a $10^{\circ} \mathrm{C}$ pode evitar injúrias, permitindo seu amadurecimento. De acordo com Caldarelli et al. (2009), o transporte em caminhões refrigerados a uma temperatura variando entre 10 e $12^{\circ} \mathrm{C}$ com a umidade relativa entre 90 a $95 \%$, possibilita o transporte do fruto por um período de 7 a 10 dias.

Logo, como resultado de todas as considerações levantadas nessa pesquisa, inferiu-se que a cadeia logística do mamão apresenta características que contribuem para uma redução na oferta da fruta, consequência dos elevados níveis de perdas e desperdícios existentes durante seu transporte e comercialização. Foram identificadas ao longo da cadeia logística do mamão características, como a utilização de caixas de madeira e transporte em caminhões abertos que são protegidos por lona, longas distâncias, comercialização a granel, principalmente para o mamão formosa e a fragilidade natural do fruto que, por ser um climatérico, continua seu processo de amadurecimento até a sua deterioração.

\section{CONCLUSÃO}

Conclui-se que a adoção de rotas curtas aliada ao transporte refrigerado para o mamão seria o cenário mais adequado para a manutenção da qualidade e consequentemente, aumento do tempo de prateleira para comercialização. Além disso, produtores e atacadistas poderiam se beneficiar com a venda de um produto de produção próxima ao local de consumo, a fim de cativar um público fiel de consumidores que estão preocupados com questões sociais e ambientais, além é claro, da agregação de valor que isso geraria ao ser comercializado. Vale destacar que neste contexto o custo de transporte também seria reduzido. Um maior dinamismo, apresentado por uma cadeia logística ajustada e eficiente pode contribuir para menores níveis de perdas e desperdícios do mamão, maior oferta do produto, sinaliza- ção dos pontos de origem mais adequados e com melhores indicadores de eficiência a partir do seu local de destino.

O resultado encontrado para o food miles do mamão foi de $1.359 \mathrm{~km}$, considerado como uma rota de distância média-longa. As longas distâncias percorridas entre a origem e destino somados aos impactos causados durante o transporte podem contribuir para um aumento dos índices de perdas e desperdícios. Isto porque durante o transporte o mamão é acondicionado em embalagens inadequadas e em caminhões não refrigerados não garantindo a preservação da fruta. Além disto, as longas distâncias implicam não só em aumento do custo de transporte, mas também numa maior emissão de $\mathrm{CO} 2$. Para futuros estudos, vale a verificação dos níveis de poluentes emitidos nas diferentes distâncias de produção. Entender e conhecer a importância de food miles permite aos usuários e principalmente, aos tomadores de decisão, pensarem em um conceito de produção e logística mais ajustada, de modo a buscar rotas mais sustentáveis e eficientes, não só em termos de custo, mas em rotas que tragam o uso racional e com menor impacto ao meio ambiente.

\section{REFERÊNCIAS}

Akaichi, F., Nayga Jr, R. M., \& Nalley, L. L. 2017. Are there tradeoffs in valuation with respect to greenhouse gas emissions, origin and food miles attributes? European Review of Agricultural Economics, 44, 3-31. https://doi.org/10.1093/erae/jbw008

Atallah, S. S., Gómez, M. I., \& Björkman, T. 2014. Localization effects for a fresh vegetable product supply chain: Broccoli in the eastern United States. Food Policy, 49, 151-159. https:// doi.org/10.1016/j.foodpol.2014.07.005

Bazzani, C., \& Canavari, M. 2017. Is local a matter of food miles or food traditions? Italian Journal of Food Science, 29, 505-517. https://doi.org/10.14674/IJFS-733

BRASIL (CONAB). Programa Brasileiro de Modernização do Mercado Hortigranjeiro - Prohort. 2018, disponível em: http://dw.ceasa.gov.br/ (acesso em 22 abr. 2020).

Caldarelli, C. E., Nakamura, C. Y., Okano, W. E., \& Ercolin, T. M. 2009. Logística do mamão Formosa: uma análise de modalidade de transporte. In 47 Congresso da Sociedade Brasileira de Economia, Administração e Sociologia Rural, Porto Alegre.

Caputo, V., Nayga Jr, R. M., \& Scarpa, R. 2013. Food miles or carbon emissions? Exploring labelling preference for food transport footprint with a stated choice study. Australian Journal of Agricultural and Resource Economics, 57, 465-482. https://doi.org/10.1111/1467-8489.12014

Carlsson-Kanyama, A. 1997. Weighted average source points and distances for consumption origin-tools for environmental impact analysis? Ecological Economics, 23, 15-23. https://doi. org/10.1016/S0921-8009(97)00566-1 
Caspi, C. E., Sorensen, G., Subramanian, S. V., \& Kawachi, I. 2012. The local food environment and diet: a systematic review. Health \& Place, 18, 1172-1187. https://doi. org/10.1016/j.healthplace.2012.05.006

Central de Abastecimento de Campinas -CEASA. 2019. Análise conjunturaldoabastecimentoecomercializaçãodaCEASACampinas em 2018. Campinas: CEASA, disponível em: http://www. ceasacampinas.com.br/sites/ceasacampinas.com.br/files/ arquivos-individuais/2019-07/RELAT\%C3\%93RIO\%20CONJUNTURAL\%202018_0.pdf (acesso em 27 abr. 2020).

Central de Abastecimento de Campinas - CEASA. 2020. Mercado de hortifrútis, disponível em: http://www.ceasacampinas.com.br/mercado-hortifrutis (acesso em 22 abr. 2020)

Coley, D., Howard, M., \& Winter, M. 2009. Local food, food miles and carbon emissions: A comparison of farm shop and mass distribution approaches. Food Policy, 34, 150-155. https://doi.org/10.1016/j.foodpol.2008.11.001

Coley, D., Howard, M., \& Winter, M. 2011. Food miles: time for a re-think? British Food Journal, 113, 919-934. http://dx.doi. org/10.1108/00070701111148432

Companhia Nacional de Abastecimento - CONAB. 2019. Centrais de abastecimento: Comercialização total de frutas e hortaliças, Vol 2 - 2018. Brasília, CONAB.

Cunha, A. R. 2015. Dimensionando o passeio das mercadorias: uma análise através dos dados do Prohort. Revista de Política Agrícola, 24, 55-63, disponível em: https://seer.sede. embrapa.br/index.php/RPA/article/view/1055 (acesso em 27 abr. 2020)

Cunha, A. R. A. A., \& Campos, J. B. 2008. Sistema Ceasa: Uma rede complexa e assimétrica de logística, XIII Seminário sobre a economia Mineira. Anais. Diamantina/MG.

Empresa Brasileira de Pesquisa Agropecuária - Embrapa. 2020, disponível em: https://www.embrapa.br/mandioca-e-fruticultura/cultivos/mamao (acesso em 18 mai. 2020).

Feagan, R. 2007. The place of food: mapping out the local in local food systems. Progress in Human Geography, 31, 23-42. https://doi.org/10.1177/0309132507073527

Feenstra, G. W. 1997. Local food systems and sustainable communities. American Journal of Alternative Agriculture, 12 28-36. https://doi.org/10.1017/S0889189300007165

Food and Agriculture Organization of the United Nations - FAO. 2013. The state of food and agriculture, disponível em: http:// www.fao.org/3/i3300e/i3300e.pdf (acesso em 24 mai. 2020).

Food and Agriculture Organization of the United Nations FAO. 2018. FAOSTAT, disponível em: http://www.fao.org/faostat/en/\#data/QC (acesso em 24 mai. 2020).

González-Muniesa, P., Mártinez-González, M. A., Hu, F. B., et al. 2017. Obesity. Nature Reviews Disease Primers, 3, 17034. https://doi.org/10.1038/nrdp.2017.34
Gustavsson, J., Cederberg, C., Sonesson, U., et al. 2011. Global food losses and food waste: extent, causes and prevention. Roma, Food and Agriculture Organization of the United Nations, disponível em: http://www.fao.org/3/a-i2697e.pdf (acesso em 24 mai. 2020).

Hirschbruch, M. D. 1998. Unidades de alimentação e nutrição: desperdício de alimentos $\mathrm{X}$ qualidade da produção. Revista Higiene Alimentar, 12, 12-14.

Instituto Brasileiro de Geografia e Estatística - IBGE. 2018. SIDRa. Produção agrícola municipal: área plantada ou destinada à colheita, área colhida, quantidade produzida, rendimento médio e valor da produção das lavouras permanentes, disponível em: https://sidra.ibge.gov.br/Tabela/5457 (acesso em 15 mai. 2020).

Kemp, K., Insch, A., Holdsworth, D. K., et al. 2010. Food miles: Do UK consumers actually care? Food Policy, 35, 504-513. https://doi.org/10.1016/j.foodpol.2010.05.011

Kissinger, M. 2012. International trade related food miles - The case of Canada. Food Policy, 37, 171-178. https://doi. org/10.1016/j.foodpol.2012.01.002

Lucena, C. C. 2016. Polos de produção de mamão no Brasil. Cruz das Almas, BA, Embrapa Mandioca e Fruticultura, disponível em: https://www.infoteca.cnptia.embrapa.br/infoteca/ bitstream/doc/1062698/1/DOC217Publica05615Cicero.pdf (acesso em 24 mai. 2020).

Malak-Rawlikowska, A., Majewski, E., Wąs, A., et al. 2019. Measuring the Economic, Environmental, and Social Sustainability of Short Food Supply Chains. Sustainability, 11, 4004. https://doi.org/10.3390/su11154004

Marques, R. W., \& Caixeta Filho, J. V. 2000. Análise das operações de transporte de frutas e hortaliças no estado de São Paulo: um estudo comparativo. In: XXXVIII Congresso Brasileiro de Economia e sociologia Rural, Rio de Janeiro.

Mosammam, H. M., Sarrafi, M., Nia, J. T., et al. 2018. Analyzing the international trade-related food miles in Iran. Outlook on Agriculture, 47, 36-43. https://doi. org/10.1177/0030727018761691

Nicholson, C. F., Gómez, M. I., \& Gao, O. H. 2011. The costs of increased localization for a multiple-product food supply chain: Dairy in the United States. Food Policy, 36, 300-310. https://doi.org/10.1016/j.foodpol.2010.11.028

Oliveira, A. L., \& Rocha, P. 2005. O papel da logística na cadeia de produção dos hortifrútis. São Paulo: IEA.

Parfitt, J., Barthel, M., \& Macnaughton, S. 2010. Food waste within food supply chains: quantification and potential for change to 2050. Philosophical Transactions of The Royal Society B: Biological Sciences, 365, 3065-3081. https://doi. org/10.1098/rstb.2010.0126

Pirog, R. S., \& Benjamin, A. 2003. Checking the food odometer: Comparing food miles for local versus conventional pro- 
duce sales to lowa institutions. Ames, lowa: Leopold Center for Sustainable Agriculture.

Pirog, R. S., \& Benjamin, A. 2005. Calculating food miles for a multiple ingredient food product. Ames, lowa: Leopold Center for Sustainable Agriculture.

Pirog, R., Van Pelt, T., Enshayan, K., e Cook, E. 2001. Food, fuel and freeways: An lowa perspective on how far food travels, fuel usage, and greenhouse gas emissions. Ames, lowa: Leopold Center for Sustainable Agriculture.

Pratt, S. 2013. Minimising food miles: Issues and outcomes in an ecotourism venture in Fiji. Journal of Sustainable Tourism, 21, 1148-1165. https://doi.org/10.1080/09669582.2013.776 060

Programa Brasileiro de Modernização do Mercado Hortigranjeiro - Prohort. 2018, disponível em: http://www. ceasacampinas.com.br/sites/ceasacampinas.com.br/files/ arquivos-individuais/2019-07/RELAT\%C3\%93RIO\%20CONJUNTURAL\%202018_0.pdf (acesso em 22 abr. 2020)

Rajkumar, P., \& Jacob, F. 2010. Business models of vegetable retailers in India. Great Lakes Herald, 4, 31-43.

Schlich, E., Biegler, I., Hardtert, B., et al. 2006. La consommation d'énergie finale de différents produits alimentaires: un essai de comparaison, Courrier de l'environnement de l'INRA, 53, décembre, 111-120.

Schmitt, E., Dominique, B., \& Six, J. 2017. Assessing the degree of localness of food value chains. Agroecology and Sustainable Food Systems, 42, 573-598. https://doi.org/10.1080/216 83565.2017.1365800
Schnell, S. M. 2013. Food miles, local eating, and community supported agriculture: putting local food in its place. Agriculture and Human Values, 30, 615-628. https://doi.org/10.1007/ s10460-013-9436-8

Sims, R. 2009. Food, place and authenticity: local food and the sustainable tourism experience. Journal of Sustainable Tourism, 17, 321-336. https://doi.org/10.1080/09669580802359293

Sirieix, L., Grolleau, G., \& Schaer, B. 2008. Do consumers care about food miles? An empirical analysis in France. International Journal of Consumer Studies, 32, 508-515. https://doi. org/10.1111/j.1470-6431.2008.00711.x

Tobarra, M. A., López, L. A., Cadarso, M. A., et al. 2018. Is seasonal households' consumption good for the nexus carbon/ water footprint? The Spanish fruits and vegetables case. Environmental science \& technology, 52, 12066-12077. https:// doi.org/10.1021/acs.est.8b00221

Van Passel, S. 2013. Food miles to assess sustainability: a revision. Sustainable Development, 21, 1-17. https://doi. org/10.1002/sd.485

Watkiss, P., Schmith, A., Tweddle, G., et al. 2005. The validity of food miles as an indicator of sustainable development: Final report. AEA Technology Environment, London, disponível em http://library.uniteddiversity.coop/Food/DEFRA_Food_ Miles_Report.pdf (acesso em 25 abr. 2020)

Weber, C. L., \& Matthews, H. S. 2008. Food-miles and the relative climate impacts of food choices in the United States. Environmental Science \& Technology, 42, 3508-3513. https://doi. org/10.1021/es702969f

Recebido: 30 maio. 2020

Aprovado: 30 jun. 2020

DOI: 10.20985/1980-5160.2020.v15n2.1646

Como citar: Aliotte, J.T.B., Lima, D.M., Oliveira, A.L.R. (2020). A contribuição do food miles na logística de transporte do mamão: do campo ao entreposto. Revista S\&G 15, 2, 131-142. https://revistasg.emnuvens.com.br/sg/article/ view/1646 